\title{
Land use and climate change on the Yamal Peninsula of north-west Siberia: some ecological and socio-economic implications
}

\author{
Bruce C. Forbes
}

\begin{abstract}
Compared to climate, land use change is expected to comprise a more important component of global change in the coming decades. However, climate is anticipated to surpass land use as a factor later in the next century, particularly in the Arctic. Discussed here are the implications of land use and climate change on the Yamal Peninsula of north-west Siberia, homeland of the Yamal Nenets. Since the discovery of super-giant natural gas fields in the 1960s, extensive exploration has resulted in the direct withdrawal of large areas for infrastructure development and associated disturbance regimes have led to cumulative impacts on thousands of additional hectares of land. The land withdrawals have pushed a relatively consistent or increasing number of reindeer onto progressively smaller parcels of pasture. This has led to excessive grazing and trampling of lichens, bryophytes and shrubs and, in many areas, erosion of sandy soils via deflation. The low Arctic tundra lies entirely within the continuous permafrost zone and ice-rich substrates are widespread. One implication of this is that both anthropogenic and zoogenic disturbance regimes may easily initiate thermokarst and aeolian erosion, leading to significant further losses of pastures. Even without industrial disturbance, a slight change of the climate would result in massive thermokarst erosion. This would have negative consequences equal to or greater than the mechanical disturbances described above. The synergistic effects of land use coupled with climate change therefore have profound implications for the ecosystems of Yamal, as well as the future of the Nenets culture, society and economy.
\end{abstract}

B. C. Forbes, Arctic Centre, University of Lapland, Box 122, SF-96101 Rovaniemi, Finland.

\section{Introduction and background}

Direct human impacts on Arctic ecosystems may be even more important than climatic change in the next few decades, including disturbance associated with resource exploitation and altered grazing regimes due to changing patterns of reindeer husbandry (Chapin et al. 1997; Callaghan et al. 1998). The challenges are to predict how community composition will respond to these environmental changes and what will be the consequences for Arctic ecosystems and the cultures that are integral components of them. This paper will discuss the implications of land use and climate change in the Yamal-Nenet Autonomous Okrug of north-west Siberia. The information summarized herein is derived from the literature as well as from field investigations carried out by the author from 1991 to 1997 , primarily on the Yamal Peninsula (Fig. 1)

The Yamal-Nenets Autonomous Okrug is home to one of the largest untapped sources of natural gas in the world which Gazprom - the state-run monopoly - intends to develop as a major source of fuel for Europe. The $\$ 40$ billion project is the last of the "Soviet"-style megaprojects (Anonymous 1998), for which Gazprom has been actively exploring since the 1960s (Vitebsky 1990). This region is the homeland of the largest remaining nomadic pastoralist group active in the Arctic, the Yamal Nenets. The basis for this indigenous but somewhat modernized economy is the seasonal exploitation of extensive tundra "pastures." There is evidence from many sites on and around the Yamal Peninsula that the system of annual migration of up to several hundred kilometres by 


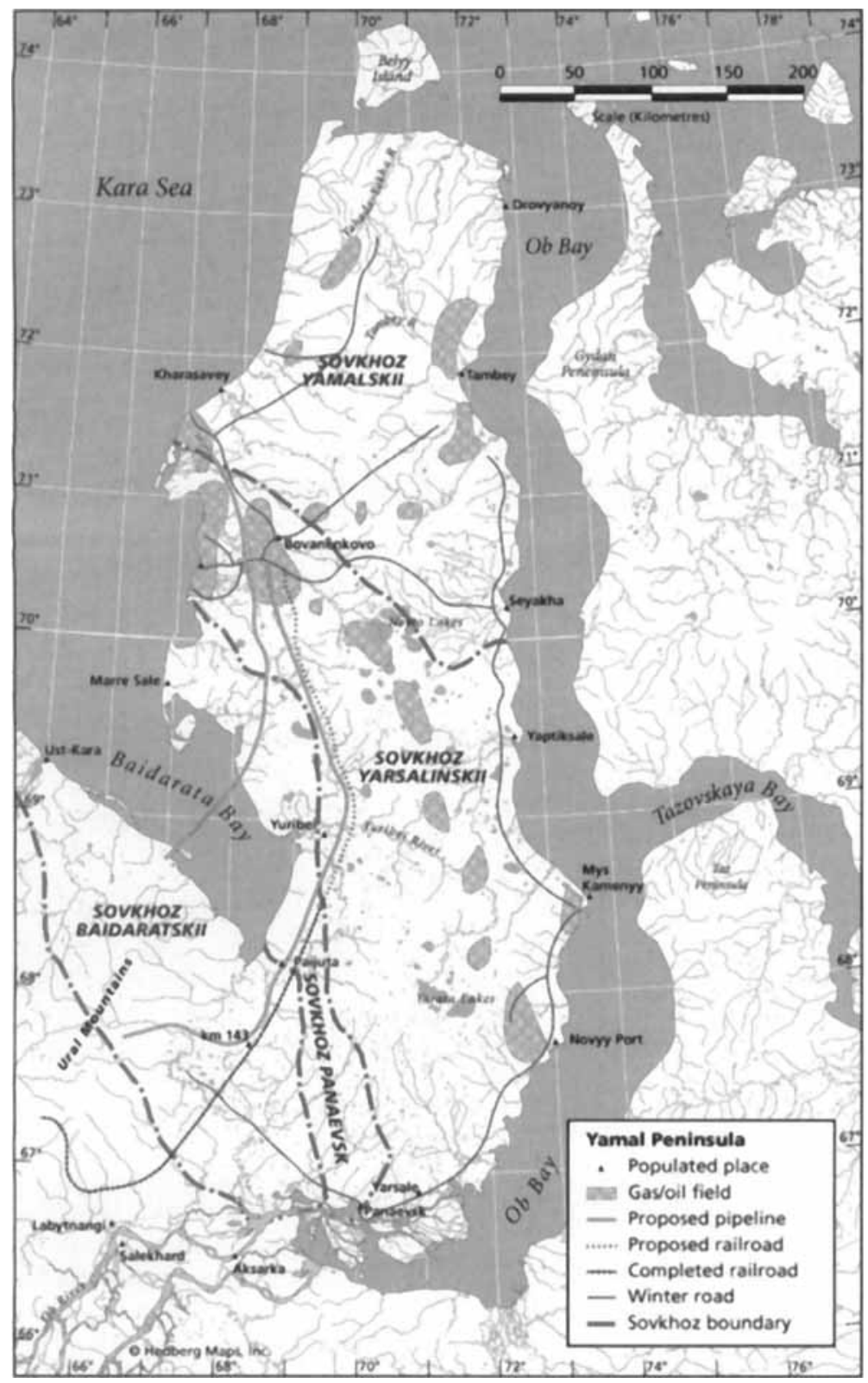

Fig. 1. Map of the Yamal Peninsula in north-west Siberia. The locations of six study sites visited by the author are indicated: Labytnangi (including Obskaya); km 143 of the railway/road (near Laborovaya); Paijuta; Yuribei; Bovanenkovo; and Kharasavey. Also indicated are the "sovkhozy," lands managed by collective reindeer breeding units. The annual reindeer migration begins at treeline, along the $\mathrm{Ob}$ River delta, and moves north onto the tundra in the spring. After utilizing the tundra as pasture all summer, the reindeer return to the south in the fall, except for in the Yamalskii sovkhoz, which exists entirely within the tundra region.

reindeer and Nenets (and their predecessors) is quite old. One such site is Yarte 6, found near the mouth of the Yuribei River on west-central Yamal. With the most recent archaeological material at Yarte 6 dating from the 11-12th century, the site has yielded evidence for domesticated reindeer as early as 600 AD (Golovnev \& Zaitsev 1992; Krupnik 1993; Fedorova 1998). However, at that time only a few reindeer were partly domesticated, perhaps only for riding or as hunting decoys. Even in the 12th century, there were probably still relatively few semi-domesticated animals compared to wild ones. It is unlikely that intensive breeding began before the 16-1700s, perhaps in response to changing environmental conditions (Krupnik 1993; Golovnev \& Osherenko 1999; W. W. Fitzhugh, pers. comm).

Plans regarding the development of the gas 
fields have been undergoing near constant revision during recent decades. There still remains indecision about the route of the potential pipeline(s), or even whether there should be any major pipeline(s) built at all. An alternative scenario under serious consideration is to build a short pipeline from Bovanenkovo to the coast at Kharasavei and take the gas out by tanker via the Northern Sea Route (Golovnev et al. 1998). Regardless of the eventual outcome, a great deal of damage has already been sustained by the ecosystems of Yamal since the advent of extensive exploration and development (Forbes 1995a, b, 1997; Khitun 1997; Vilchek 1997), including health and demographic problems among the indigenous population (Pika \& Bogoyavlensky 1995). Even if the Northern Sea Route is chosen, the amount of damage to terrestrial and aquatic ecosystems is expected to increase dramatically, with an essentially inestimable impact on the Nenets themselves (Golovnev et al. 1998; Golovnev \& Osherenko 1999).

\section{Landscapes and disturbance regimes}

The Yamal Peninsula is situated in the north of the Tyumen Oblast, and lies entirely within the low Arctic tundra (sensu Bliss \& Matveyeva 1992) and continuous permafrost zones. Ice-rich permafrost is common and the landscapes range from moderately to highly unstable (Vilchek \& Bykova 1992; Nelson \& Anisimov 1993). This area is characterized by relatively homogeneous surficial materials (Pleistocene sands underlain by marine clays) and a pronounced lack of relief (maximum elevation is ca. $80 \mathrm{~m}$ ) (Dobrinskii 1995). Lowland organic soils in the predominant mires are generally acidic ( $\mathrm{pH} 4.5-5.6)$ and Sphagnum spp. are among the most abundant mosses (Botch et al. 1971), whereas upland and frost-boil areas with exposed mineral soils are closer to neutral (pH 6.4-6.8). Meltzer (1984) describes the major plant communities. Upright shrubs are common on slopes in the southernmost portions of the Yamal Peninsula, and especially in riparian zones. Shrub willows are generally $<30 \mathrm{~cm}$ in height over the majority of the peninsula, although individuals of both alder and willow $>1 \mathrm{~m}$ occur in riparian zones, particularly in the south. The relative biodiversity of Yamal on a global scale is insignificant, but does include some rare and ecologically vulnerable species. About 10 species of birds and small mammals and seven species of vascular plants are listed in the Red Book (Chernov 1997), and it seems that none are listed due to being understudied.

The Yamal Peninsula is extensively grazed in summer by large reindeer herds belonging to the Nenets, aboriginal nomadic pastoralists. In this context it is important to note that the number of reindeer on Yamal Peninsula - ca. 180000 and currently increasing - is already estimated to be 1.5 to 2 times greater than the optimum for the region (Vilchek \& Bykova 1992; Martens et al. 1996). Reindeer greatly affect community structure and productivity via their trampling and grazing. For example, cover of virtually all lichens, especially those fruticose species most preferred by reindeer (Podkoritov 1995), is minimal and ruderal species are prominent (e.g. Forbes 1995b). In addition, the cover of grasses is increasing in many areas - so-called "grassification" - at the expense of dwarf shrubs and lichens (Martens et al. 1996).

The regional scale of habitat destruction in north-west Siberia, including the Yamal Peninsula, was recently summarized by Vilchek \& Bykova (1992; see also Vilchek 1997). They observed that plant cover is already completely destroyed over $450 \mathrm{~km}^{2}$ within gas and oil fields and $1800 \mathrm{~km}^{2}$ along the main pipelines. They estimate the total area of destroyed vegetation to be about $2500 \mathrm{~km}^{2}$. Based on the Tyumen Oblast's present plans, they assert that the area of explored gas and oil fields will increase to $16200 \mathrm{~km}^{2}$ and the portion with completely destroyed vegetation will increase to $5500 \mathrm{~km}^{2}$.

These figures can be misleading because they do not include the further degradation that is expected to occur due to overgrazing by reindeer, nor cumulative impacts (sensu Walker 1997) such as altered hydrology and blowing sand/dust from roads and quarries (e.g. Forbes 1995b). The three most widespread types of disturbance are off-road vehicle traffic, exploratory drilling, and sand excavation (Vilchek \& Bykova 1992; Khitun 1997). Exploration and development activities at the Bovanenkovo Gas Field alone had, by 1990 , led to the loss of $127000 \mathrm{ha}\left(1270 \mathrm{~km}^{2}\right)$ of tundra comprising reindeer pasture land (Martens et al. 1996). This process, combined with massive outright land withdrawals by Gazprom and cumulative impacts (see Discussion below), has pushed a relatively consistent number of animals 
onto increasingly smaller areas of tundra suitable for grazing. Assisted revegetation programmes designed to control erosion on affected areas have met with limited success due to their immense expanse and the prevalence of nutrient-poor, welldrained and highly erodable sands, in conjunction with the cold, dry climate (Martens 1995; Forbes \& Jefferies 1999).

In terms of the surface area covered, roads and off-road vehicle traffic are two of the most extensive anthropogenic disturbance types in boreal and Arctic regions, with numerous direct and cumulative impacts (Forbes 1992, 1995a, 1998; Walker 1997). Rapid and relatively cryptic but significant effects include changes in hydrology, with the result that some wetlands are drained, although waterlogging is more common (Martens et al. 1996). On southern Yamal, both a railway and an adjacent service road have been constructed since the late 1980s between Obskaya and Paijuta, a distance of more than $210 \mathrm{~km}$. This transport corridor continues to expand further north each year on the western portion of the peninsula, supplying labour and materials for the infrastructure that will eventually support construction of the gas pipeline(s) from Bovanenkovo, either north-west to Kharasavei or south-west to the existing pipeline network.

\section{Discussion}

The frozen ground beneath Yamal is characterized as "warm" permafrost with its temperature amplitude not far below $0^{\circ} \mathrm{C}$. Permafrost is considered to be a sensitive indicator of climate change and monitoring of frozen ground in Alaska and northwest Siberia has shown that the substrates in both regions have been warming in recent years (Pavlov 1994) in conjunction with climate patterns in the northern hemisphere. This is causing some alarm in northern Alaska, as is indicated by recent coverage in the mainstream media (Stevens 1998). Even without industrial disturbance, a slight change of the climate, with warmer spring and summer temperatures and additional precipitation, is expected to result in massive thermokarst erosion throughout the entire West Siberian Basin (Nelson \& Anisimov 1993; Williams 1995; Anisimov \& Nelson 1997).

In truth, many disturbances associated with petroleum development are mesoscale in extent $\left(<1 \mathrm{~km}^{2}\right)$, often approaching microsite $\left(<100 \mathrm{~m}^{2}\right)$ dimensions (Walker \& Walker 1991) and in total they occupy small proportions $(<10 \%)$ of oil and gas fields (Walker et al. 1987). Nevertheless, we must acknowledge the effect of "nibbling" (sensu Walker 1997), a slow but essentially permanent change of large regions effected by many seemingly insignificant perturbations. Even minimal damage from off-road vehicle traffic and seismic survey equipment, particularly in summer but also in winter where snow cover is thin, is capable of significantly warming soils, increasing active layer depths and initiating the melting of ground ice (Crampton 1977; Lawson 1986; Forbes 1998). Blowing sand from abandoned quarries and dust emanating from roads result in numerous cumulative impacts, including spoiling berries and mushrooms, eliminating Sphagnum mosses and lichens, and rapidly altering plant communities via either burial (from sand) or chemistry (high alkalinity road dust); all of these are cited by the Nenets as major concerns (Forbes 1995b).

It has also been demonstrated that small-scale changes can affect wildlife populations out of proportion to the landscape area involved when they provide scarce nutritional requirements. For example, caribou in Arctic Alaska have been known to feed preferentially on vegetation growing in some disturbed areas associated with oil development (Truett et al. 1994). Yet, other disturbances within the same oil field may repel animals (Nellemann \& Cameron 1996). Either way, natural feeding patterns are altered indefinitely. On Yamal, herders endeavour to steer their reindeer to avoid even small camps where they can see that crew workers have been because of rusted metal, broken glass and other trash left on the tundra which easily cuts open the animals' hooves. At the very least, this type of injury slows down the animal and, perhaps, the brigade and, at worst, can lead to serious infection (Podkoritov 1995).

Problems related to natural and assisted tundra revegetation are particularly acute in the summer pastures on the Yamal Peninsula, where the combination of increasingly intensive reindeer grazing and trampling, coupled with industrial petroleum development, is significantly augmenting the rate and scope of surface disturbance (Korytin et al. 1995; Podkoritov 1995). In addition to direct impacts, there are cumulative impacts associated with grazing which include: greatly accelerated deflation of exposed sands; thinning, warming and cratering of the vegetation mat; 
increased soil infiltration rates resulting in massive thermokarst and landslides; and altered hydrology and drying of soils in drained areas (Forbes 1995b, 1997; Khitun 1997; Vilchek 1997).

To conclude, it is important to realize that Nenets culture and society are essentially intact and remain remarkably vibrant even after centuries of attempts by outside forces to "assimilate" or otherwise exert control over them (Golovnev \& Osherenko 1999). However, the ecosystems, which form the basis for the indigenous economy, have already sustained extensive and, in many areas, intensive and irreparable damage. The northern tundra pastures and southern foresttundra lichen stands are at the crux of the situation, forming the core feeding areas at either end of the annual migration route.

As has been discussed, the region is vast and the amount of overall industrial disturbance seems small when calculated as a percentage of the total land area. Nonetheless, as Nenets are quick to point out, the developers always take the best lands - higher, drier ground - for creating infrastructure (Alexander 1994; Forbes, pers. obs.). In an area as flat as Yamal, dominated by mires and lakes, this quickly puts additional, unsustainable pressure on the remaining relatively high ground, such as ancient sand dunes, which is exploited by the reindeer for insect relief in summer (see also Helle \& Aspi 1984). Heavy trampling and grazing on these areas is initiating deflation of sands on previously stable ground and exacerbating erosion and inhibiting vegetation regeneration on older exposures (Pristyazhnyuk 1997; Forbes, unpubl. data).

As the number of reindeer either remains stable or continues to increase, the threat of desertification looms large (Vilchek 1997). All parties acknowledge that the pastures are in poor condition at present (Korytin et al. 1995; Podkoritov 1995; Martens et al. 1996; M. N. Okotetto, pers. comm.). Industry blames the Nenets, claiming they simply have too many reindeer. The Nenets, more plausibly, attribute the problems to a variety of chronic factors. These include: (i) long-term restrictions placed on them by the Soviet-induced "brigade" system of management, which (a) directed movement of animals within narrow corridors, thus robbing them of the freedom needed to adjust for changes in climate and pasture conditions and (b) put lichen-rich areas previously kept in reserve for emergencies into continuous use; (ii) the slow but steady removal of pasture lands via either (a) de facto "withdrawal" for infrastructure or (b) default withdrawal via genuine degradation (e.g. pollution, dust, sand) or prudent avoidance behaviour on the part of herders.

In the final analysis, Yamal requires a system of management that is sensitive to rather wideranging temporal and spatial scales. In the short term, e.g. the next two to three decades, there are critical and immediate threats from changes in land use, including both local and widespread damages from industry and the ecosystem-level effects of reindeer husbandry. In the longer term, if the climatic warming already underway continues, we can expect extensive alteration of the existing tundra communities as permafrost begins to thaw and large areas are either denuded by landslides (cf. Leibman \& Egorov 1996) or inundated by melting ground ice via thermokarst. Planning to cope with such changes will require: (a) much greater efforts on the part of industry to prevent or mitigate additional disturbance; (b) a flexible system of land use, emphasizing property rights, that is satisfactory to both the Nenets and the State; and (c) additional knowledge on the composition and potential forage utility of emergent plant communities which will necessarily be exploited by the reindeer.

Acknowledgements. - Research that contributed to the interpretations reported here was funded by generous grants from the National Geographic Society and NATO's Scientific and Environmental Affairs Division. I am grateful for constructive comments provided by the two anonymous reviewers.

\section{References}

Alexander, B. 1994: Gas development means trouble in the pipeline for Siberia's reindeer herders. Int. Wildlife Mag. June, 4-11.

Anisimov, O. A. \& Nelson, F. E. 1997: Permafrost zonation and climate change in the Northern Hemisphere: results from transient general circulation models. Climatic Change 35, 241-258.

Anonymous 1998: Gazprom: emerging Europe oil and gas. Shareholder's report from 12 December 1997, updated 9 July 1998. Deutsche Morgan Grenfell. 56 pp. London: Morgan Grenfell \& Co.

Bliss, L. C. \& Matveyeva, N. V. 1992: Circumpolar Arctic vegetation. In F. S. Chapin III et al. (eds): Arctic ecosystems in a changing climate: an ecophysiological perspective. $\mathrm{Pp}$. 59-89. New York: Academic Press. 
Botch, M. C., Gerasimenko, T. V. \& Tolchelnikov, Y. C. 1971: Bolota Yamala. (Mires of the Yamal region.) Bot. Zhur, 56, $1421-1435$

Callaghan, T. V., Körner, C., Heal, O. W., Lee, S. E. \& Cornelissen, J. H. C. 1998: Scenarios for ecosystem responses to global change. In O.W. Heal et al. (eds.): Global change in Europe's cold regions. Ecosystems Research Report 27, 11-62.

Chapin, F. S. III, Hobbie, S. E. \& Shaver, G. R. 1997: Impacts of global change on the composition of Arctic communities: implications for ecosystem functioning. In W. C. Oechel et al. (eds.): Global change and Arctic terrestrial ecosystems. Pp. 221-228. New York: Springer.

Chernov, Yu. I. (ed.) 1997: Krasnoye Kniga Yamalo-Nenetskii Avtonomo Okrug. (Red Book of the Yamal-Nenets Autonomous Okrug.) Ekaterinburg: Urals University Press.

Crampton, C. B. 1977: A study of the dynamics of hummocky microrelief in the Canadian north. Can. J. Earth Sci. 14, 639-649.

Dobrinskii, L. N. (ed.) 1995: Priroda Yamala. (The nature of Yamal.) Ekaterinburg (Russia): Nauka.

Fedorova, N. (ed.) 1998: Ushedshie v kholmy. (Gone to the hills: culture of the coastal residents of the Yamal Peninsula during the Iron Age.) Ekaterinburg (Russia): History and Archaeology Institute.

Forbes, B. C. 1992: History, ecology and biogeography of anthropogenic disturbance along the upper Steese Highway, interior Alaska. J. North. Sci. 4, 1-15.

Forbes, B. C. 1995a: Effects of surface disturbance on the movement of native and exotic plants under a changing climate. In T. V. Callaghan (ed.): Global change and Arctic terrestrial ecosystems. Ecosystems Research Report 10, 209-219.

Forbes, B. C. 1995b: Tundra disturbance studies. III. Short-term effects of acolian sand and dust, Yamal Region, northwest Siberia, Russia. Env. Conserv. 22, 335-344.

Forbes, B. C. 1997: Tundra disturbance studies. IV. Species establishment on anthropogenic primary surfaces, Yamal Peninsula, northwest Siberia, Russia. Polar Geogr. 21, 79-100.

Forbes, B. C. 1998: Cumulative impacts of vehicle traffic on high Arctic tundra: soil temperature, plant biomass, species richness and mineral nutrition. Nordicana 57, 269-274.

Forbes, B. C. \& Jefferies, R. L. 1999: Revegetation in Arctic landscapes: constraints and applications. Biol. Conserv. 88, 15-24.

Golovnev, A. V. \& Osherenko, G. 1999: Siberian survival: the Nenets and their story. Ithaca, NY: Cornell University Press.

Golovnev, A. V. \& Zaitsev, G. S. 1992: Istoria Yamala. (History of the Yamal.) Tobolsk-Yar Sale (Russia): Ethnographic Bureau.

Golovnev, A. V., Osherenko, G., Pribylskii, Yu. P. \& Schindler, D. L. 1998. Indigenous peoples and the development of the Yamal Peninsula. INSROP Working Paper No. 112. Lysaker (Norway): Fridtjof Nansen Institute.

Helle, T. \& Aspi, J. 1984: Do sandy patches help reindeer against insects? Rep. Kevo Subarctic Field Sta. 19, 57-62.

Khitun, O. 1997: Self-recovery after technogenic and natural disturbances in the central part of the Yamal Peninsula (western Siberian Arctic). In R. M. M. Crawford (ed.): Disturbance and recovery in Arctic lands: an ecological perspective. Pp. 531-562. Dordrecht: Kluwer Academic.

Korytin, N. S., Bogdanov, V. D., Bykov, V. V., Zharkov, A. A., Magomedova, M. A. \& Matveychiyuk, S. P. 1995: Traditsion- oye ispolzovaniye biologicheski resursov. (Traditional usage of biological natural resources.) In L. N. Dobrinskii (ed.): Priroda Yamala. (The nature of Yamal.) Pp. 383-406. Ekaterinburg (Russia): Nauka.

Krupnik, I. 1993: Arctic adaptations: native whalers and reindeer herders of northern Eurasia. 355 pp. Hanover, $\mathrm{NH}$ (USA): University Press of New England.

Lawson, D. E. 1986: Response of permafrost terrain to disturbance: a synthesis of observations from northern Alaska, USA. Arct. Alp. Res. 18, 1-17.

Leibman, M. O. \& Egorov, I. P. 1996: Climatic and environmental controls of cryogenic landslides, Yamal, Russia. In K. Senneset (ed.): Landslides. Pp. 1941-1946. Rotterdam: A. A. Balkema.

Martens, H. 1995: Revegetation research western Siberia: year 4. Report prepared for AMOCO Eurasia Production Co. 38 pp. Calgary, Canada: Harvey Martens \& Assoc.

Martens, H., M. Magomedova \& L. Morozova. 1996: Rangeland studies in the Bovanenkovo Proposed Development Area: year 3. Report prepared for AMOCO Eurasia Production Co. 35 pp. Calgary, Canada: Harvey Martens \& Assoc.

Meltzer, L. I. 1984: Zonalnoye delyeniye rastitelnosti tundry Zapadno-Sibirskoi ravniny. (Zonal division of tundra vegetation of the West Siberian plain.) In A. V. Belov (ed.): Rastitelnost Zapadnoi Sibiri i ye kartografirovaniye. (Vegetation of western Siberia and its mapping.) Pp. 7-19. Novosibirsk (Russia): Akademia Nauk.

Nellemann, C. \& Cameron, R. D. 1996: Effects of petroleum development on terrain preferences of calving caribou. Arctic 49, 23-28.

Nelson, F. E. \& Anisimov, O. A. 1993: Permafrost zonation in Russia under anthropogenic climatic change. Permafrost Perigl. Proc. 4, 137-148.

Pavlov, A. V. 1994: Current changes of climate and permafrost in the Arctic and sub-Arctic of Russia. Permafrost Perigl. Proc. 5, 101-110.

Pika, A. \& Bogoyavlensky, D. 1995: Yamal Peninsula: oil and gas development and problems of demography and health among indigenous populations. Arctic Anthro. 32, 61-74.

Podkoritov, F. M. 1995: Olyenedstvo Yamala. (Reindeer herding on Yamal.) 274 pp. Sosnovyi Bor: Leningrad Atomic Electrical Station.

Pristyazhnyuk, S. A. 1997: The reestablishment of shrub-mosslichen communities on sandy deflation plots in the Yamal tundra. In E. G. Kuznetsova \& I. B. Archegova (eds.): Development of the north and problems of recultivation. $\mathrm{Pp}$. 145-146. Syktyvkar (Russia): Komi Science Centre.

Stevens, W. K. 1998: Dead trees and shriveling glaciers as Alaska melts. New York Times 18 August, pp. F1, F5.

Truett, J. C., Senner, R. G. B., Kertell, K., Rodrigues, R. \& Pollard, R. H. 1994: Wildlife responses to small-scale disturbances in Arctic tundra. Wildlife Soc. Bull. 22, 317-324.

Tsibulsky, V. R., Valeeva, E. I., Arefiev, S. P., Meltzer, L. I., Moskovchenko, D. V., Gashev, S. N., Brusynina, I. N. \& Sharpova, T. S. 1995: Prirodnaya sreda Yamala. (Environmental nature of Yamal.) Vol. 2. 104 pp. Tyumen (Russia): Institute of Northern Development.

Vilchek, G. E. 1997: Arctic ecosystem stability and disturbance: a West Siberian case history. In R. M. M. Crawford (ed.): Disturbance and recovery in Arctic lands: an ecological perspective. Pp. 179-189. Dordrecht: Kluwer Academic. 
Vilchek, G. E. \& Bykova, O. Y. 1992: The origin of regional ecological problems within the northern Tyumen Oblast. Russia, Arct. Alp. Res. 24, 99-107.

Vitebsky, P. 1990: Gas, environmentalism and native anxieties in the Soviet Arctic: the case of Yamal Peninsula. Polar Rec. 26, 19-26.

Walker, D. A. 1997: Arctic Alaskan vegetation disturbance and recovery: a hierarchic approach to the issue of cumulative impacts. In R. M. M. Crawford (ed.): Disturbance and recovery in Arctic lands: an ecological perspective. $\mathrm{Pp}$. 457-479. Dordrecht: Kluwer Academic.
Walker, D. A. \& Walker, M. D. 1991: History and pattern of disturbance in Alaskan Arctic terrestrial ecosystems: a hierarchical approach to analysing landscape change. J. Appl. Ecol. 28, 244-276.

Walker, D. A., Webber, P. J., Binnian, E. F., Everett, K. R., Lederer, N. D., Nordstrand, E. A. \& Walker, M. D. 1987: Cumulative impacts of oil fields on northern Alaskan landscapes. Science 238, 757-761.

Williams, P. J. 1995: Permafrost and climate change: geotechnical implications. Phil. Trans. Roy. Soc. Lond. A352, $347-358$. 